\title{
ESTUDOS DE BEBÊS: LINHAS E PERSPECTIVAS DE UM CAMPO EM CONSTRUÇÃO
}

\author{
BABY STUDIES: LINES AND PERSPECTIVES OF A FIELD \\ BEING CONSTRUCTED
}

\section{ESTUDIOS DE BEBÉS: LÍNEAS Y PERSPECTIVAS DE UN CAMPO EN CONSTRUCCIÓN}

Gabriela de Campos Tebet ${ }^{1}$; Anete Abramowicz ${ }^{2}$

\begin{abstract}
RESUMO
Este artigo se propõe a integrar e contribuir para compor o campo epistemológico e metodológico denominado "Estudos de bebês" nas ciências sociais e humanas. A partir de pesquisa bibliográfica, identificaram-se contribuições da História, Medicina, Psicologia e Psicanálise, Antropologia, Sociologia, Pedagogia, Filosofia e Geografia para o campo em construção. Argumenta-se que a ideia de criança, entendida como uma figura conceitual que sustenta os Estudos da infância, não abarca os bebês. Os resultados da pesquisa indicam produções e debates que podem contribuir para compor um território no qual bebês estejam presentes e sejam centrais. A partir das linhas traçadas e de uma aproximação com uma perspectiva pós-estrutural, apresenta-se uma proposta de compreensão epistemológica da figura Bebê. Indica-se, como abordagens promissoras para os Estudos de bebês, perspectivas metodológicas em construção, pautadas nas cartografia e nos mapas de trajetos, na medida em que poderiam permitir aos investigadores seguir os minúsculos, mesmo que mínimos, gestos e eventos que compõem as vidas dos bebês e contribuir para uma melhor compreensão deles a partir de suas próprias perspectivas.
\end{abstract}

PALAVRAS-CHAVE: Criança. Recém-nascido. Infância. Cartografia. Ciências Sociais.

\section{ABSTRACT}

This article proposes to integrate and contribute to compose the epistemological and methodological field denominated "Baby Studies " in the social and human sciences. From bibliographical research, contributions of History, Medicine, Psychology and Psychoanalysis, Anthropology, Sociology, Pedagogy, Philosophy and Geography were identified for the field under construction. It is argued that the idea of the child, understood as a conceptual figure that supports the studies of childhood, does not include babies. The results of research indicate productions and debates that can contribute to forming a territory in which babies are present and central. From the lines drawn and from an approach with a poststructural perspective, a proposal of epistemological understanding of the figure Baby is presented. It is pointed out, as promising approaches for Baby Studies, methodological perspectives under construction, based on cartography and on route maps, in so far as it could allow researchers to follow the miniscule, even minimums, gestures and events that compose lives of babies, contributing to a better understanding of babies from their perspective

KEYWORDS: Children. Infants. Childhood. Cartography. Social Sciences.

\footnotetext{
${ }^{1}$ Doutora em Educação - Universidade Federal de São Carlos (UFSCAR) - São Carlos, SP - Brasil. Professora Doutora - Universidade Estadual de Campinas (UNICAMP) - Campinas, SP - Brasil. E-mail: gabrielagtebet@yahoo.com.br

${ }^{2}$ Doutora em Educação - Universidade Estadual de Campinas (UNICAMP) - Campinas, SP - Brasil. Professora Titular - Universidade de São Paulo (USP) - São Paulo, SP - Brasil. E-mail: aneteabramo@gmail.com

Submetido em: 08/06/2017 - Acesso em: 20/02/2018
} 


\section{RESUMEN}

Este artículo se propone a integrar y contribuir a componer el campo epistemológico y metodológico denominado "Estudios de bebés" en las ciencias sociales y humanas. A partir de la investigación bibliográfica, se identificaron contribuciones de la Historia, Medicina, Psicología y Psicoanálisis, Antropología, Sociología, Pedagogía, Filosofía y Geografía para el campo en construcción. Se argumenta que la idea de niño, entendida como una figura conceptual que sostiene los Estudios de la infancia, no abarca a los bebés. Los resultados de la investigación indican producciones y debates que pueden contribuir a componer un territorio en el cual los bebés estén presentes y sean centrales. A partir de las líneas trazadas y de una aproximación con una perspectiva post-estructural, se presenta una propuesta de comprensión epistemológica de la figura Bebé y se indican, como enfoques prometedores para los Estudios de bebés, perspectivas metodológicas en construcción, pautadas en las cartografías y en los mapas de trayectos e intensidades, en la medida en que podrían permitir a los investigadores seguir los minúsculos, aunque mínimos, gestos y eventos que componen las vidas de los bebés y contribuir a una mejor comprensión de ellos a partir de sus propias perspectivas.

PALABRAS CLAVE: Niños, Bebé, Niñez, Cartografía, Ciencias Sociales

\section{INTRODUÇÃO: ENCONTRAR UM LUGAR NAS CIÊNCIAS SOCIAIS PARA ESTUDAR OS BEBÊS}

os Estudos da Infância não têm incluído bebês. Eu não acho que incluiu. E isso é absolutamente correto e deveria ser incluído. Talvez seja mais desafiador, nós não podemos entrevistar um bebê facilmente, você precisa observá-los, você precisa trabalhar de outras formas. (JAMES apud PIRES; NASCIMENTO, 2014, p. 942)

A dificuldade dos pesquisadores para compreender bebês e a necessidade de um olhar especial e metodologias específicas para diagramá-los, destacada nessa fala de James e já apontada por Gottlieb (2009), talvez seja um dos principais motivos de terem os bebês permanecido por tanto tempo longe do interesse dos estudiosos da infância.

Estudo teórico realizado a partir da análise da literatura sobre Sociologia da infância (TEBET; ABRAMOWICZ, 2014) aponta para insuficientes contribuições no campo e argumenta que a principal razão para isso é o fato de que os bebês não são crianças $^{3}$. Isso significa dizer que os aportes teóricos, epistemológicos e metodológicos que são, de alguma maneira, "suficientes" para compreender as crianças não podem ser simplesmente decalcados ou transpostos para a compreensão de bebês.

Assim, os principais conceitos e metodologias subjacentes à sociologia da infância não seriam facilmente adaptáveis, e os conceitos, mais especificamente, não necessariamente seriam sempre adequados para pesquisas com os bebês. Os bebês fazem experiência e se envolvem em processos múltiplos de subjetivações. Qual experiência de tempo e de espaço experimentam eles em seus minúsculos gestos? Como diagramar essas experiências e ampliar nosso cardápio epistemológico, hoje voltado às experiências das crianças em geral?

Não se trata, portanto, de estudar bebês de maneira a configurar uma espécie de

\footnotetext{
${ }^{3}$ Kohan (2007, p. 100) ao discutir Infância e Filosofia também afirma que em geral a palavra "infans" não se remete aos bebês.
} 
bebê universal, nem tampouco o coletivo dos bebês, mas de compreender o que vem a ser "um bebê"; que figura conceitual é essa?

Neste artigo o debate proposto sobre bebês não se fundamenta em uma compreensão estrutural, que poderia nos levar a afirmá-los como parte da estrutura geracional que denominamos infância. Muito menos se fundamenta em uma perspectiva que poderia ser definida por uma idade específica. Pautar-nos-emos nas proposições desenvolvidas por Prout e colaboradores em diversas publicações, para pensar em que o bebê, como figura conceitual, se distingue da criança. Não se trata, portanto, de definir o que nós consideramos como bebês e de estabelecer aqui fronteiras rígidas entre gerações ou fases da infância, mas de evidenciar como a produção científica tem compreendido os bebês e como em nossa sociedade a ideia de bebê não se confunde com a ideia de criança ${ }^{4}$.

A partir de um diálogo com o pensamento pós-estruturalista, consideramos que

o conceito de sujeito que existe fora das relações sociais é uma herança do dualismo cartesiano que ainda precisa ser superada nas ciências sociais. Enquanto - Estruturalismo resolveu esse dualismo (ou binarismo, como o temos denominado) abolindo o sujeito e fazendo dos indivíduos simples possuidores de relações sociais, o pensamento pós-estruturalista conserva o sujeito fazendo deles, os efeitos do discurso. (JAMES; PROUT, 1997, p. 24)

Desse modo, os autores argumentam que, ao invés de buscar o que seria uma "criança real" ou a "experiência autêntica da infância", os Estudos da Infância deveriam buscar realizar "a análise do modo como diferentes práticas discursivas produzem diferentes infâncias, cada uma e todas elas 'reais' em seus próprios regimes de verdade" (JAMES; PROUT, 1997, p. 26). No que diz respeito aos Bebês, a partir dessa perspectiva e tentando dialogar com questões formuladas por Barbosa, Delgado e Tomás (2016, p. 106) sobre "o que define um bebê?", entendemos que, por um lado, o contexto social e histórico nos quais se constroem discursos e práticas específicos é responsável por defini-los; e por outro, a maneira pela qual eles se constituem como sujeitos, se subjetivam, se singularizam também colabora para conformá-los. Portanto, há duas tarefas complexas para serem realizadas nos estudos dos bebês: compreender como os discursos sobre eles se proliferam, se constituem e se diferenciam dos discursos sobre as crianças e, além disso, compreender a maneira pela qual eles se individuam, se subjetivam e se singularizam de maneira "original" e que lhes é própria.

Assim, iniciamos o texto apresentando o modo como um conjunto de publicações

\footnotetext{
${ }^{4}$ Nesse sentido, entendemos que as definições presentes, por exemplo, no documento Práticas cotidianas na Educação Infantil: bases para a reflexão sobre as orientações curriculares (Brasil, 2009), que compreende bebês como crianças de 0 a 18 meses e crianças bem pequenas como crianças entre 19 meses e 3 anos e 11 meses, se configuram como um dos discursos recentes, mas estabelecem uma ordenação jurídica, etária, do que são os bebês.
} 
tem trazido os bebês para o centro dos debates acadêmicos no âmbito de diversas disciplinas e em diversos contextos geográficos. Tais pesquisas mostram que olhar para os bebês, em qualquer campo de estudos, implica reconhecer suas especificidades e também as limitações do campo da infância para o seu estudo. $O$ estudo de bebês não pode se restringir aos conceitos e às metodologias tradicionalmente utilizados para pesquisar crianças. Há que compreender as singularidades e construir para eles um espaço adequado na produção acadêmica, para poder aproveitar toda a potência neles presente.

Assim, ao apontar a contribuição de diversos campos de conhecimento, como a História, a Psicologia, a Antropologia, a Filosofia, a Geografia, etc., estamos contribuindo para ultrapassar o domínio da Sociologia que se apresentava nos Estudos da criança/Estudos da infância e oferecendo aportes para o desenvolvimento de um território interdisciplinar de estudos para pensar os bebês com contribuições de pesquisadores com formações, origens geográficas e tradições de pesquisas distintas.

\section{A HISTÓRIA E OS BEBÊS}

A obra de Ariès (1981) é clássica, na medida em que dá um estatuto social e histórico à infância, mostrando diferenças ao longo da história. O autor aponta para o fato de existir uma história social da infância e da criança. Mostra a emergência da criança na modernidade e indica que ela emerge em um determinado momento, que "dá a ver", visibiliza e também enuncia a criança a partir de diversas forças, entre elas: econômicas, sociais, estéticas, literárias, médicas, sanitárias, pedagógicas, etc., que fizeram emergir, a partir do século XVIII, uma forma específica de ser denominada criança.

Do mesmo modo, propomos pensar a emergência de bebês a partir de outras ferramentas analíticas, com o cuidado de, ao diagramá-los, não sobrepor dispositivos de controle, normatização e normalização do que é ser bebê.

Para entrar nesse território de bebês, buscamos entender como a sociedade se relacionou com eles ao longo da história. Nessa perspectiva, são significativos os estudos desenvolvidos por Fontanel e D'Harcourt (2010). As autoras apontam para o fato de que o uso do espaço pelos bebês ao longo da história e as relações sociais se modificaram radicalmente em razão das compreensões e das práticas adotadas em relação a eles. A experiência espacial vivida por um bebê antes do século XVIII, em alguns países da Europa, como na França, por exemplo, todo enfaixado e incapaz de explorar sequer o seu próprio corpo, como nos mostram as imagens presentes no livro de Fontanel e d'Harcourt (2010), é completamente distinta da que vive um bebê moderno, livre dessa faixa e do significado dela como um dispositivo de controle do corpo. 


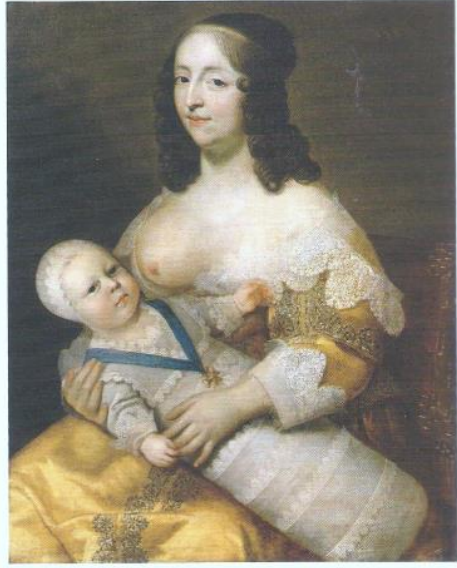

FIGURA 1 - Louis XIV et la Dame Longuet de La Giraudière (Louis XIV and his Wet Nurse) by Charles Beaubrun, c. $164081 \times 64 \mathrm{~cm}$ Musée National du Château et des Trianons, Versailles. Fonte: Fontanel e D'Harcourt (2010, p. 70)

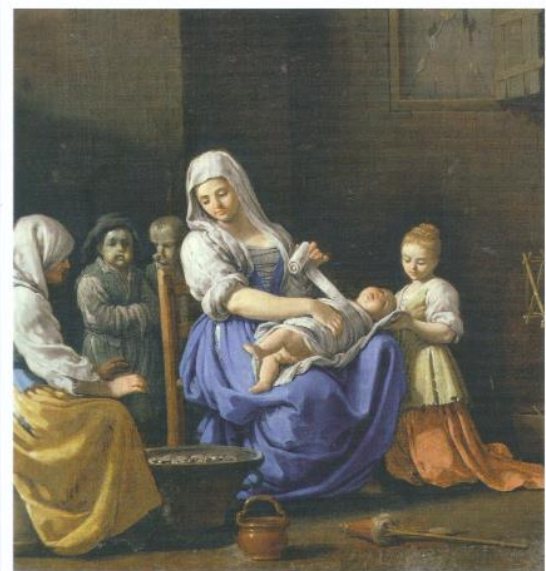

FIGURA 2 - L'Hiver, vers 1721-1727, Giuseppe Gabarini, Pinacothèque nationale, Bologne. Fonte: Fontanel e D'Harcourt (2010, p. 103)

Os estudos de Fontanel e D'Harcourt (2010) mostram ainda como ao longo da história se modificaram os dispositivos utilizados para manter os bebês eretos, ensiná-los a caminhar, alimentá-los, lavá-los e transportá-los, etc. E, com isso, como mudaram também as práticas sociais a eles associadas, assim como o lugar que eles ocupam nas relações sociais.

\section{A MEDICINA, A PSICOLOGIA, A PSICANÁLISE E OS BEBÊS}

Do ponto de vista da Medicina, da Psicologia e da Psicanálise, não podemos deixar de mencionar as contribuições, para os Estudos de bebês, de autores como Melanie Klein, Ana Freud, Henri Wallon, Donald Winnicott, Françoise Dolto e Emmi Pikler. Contudo, ainda que de algum modo todos eles tenham contribuído para o estudo das crianças bem pequenas e dos bebês, gostaríamos aqui de destacar a constituição de aportes que tenham diferenciado os bebês das crianças e contribuído para construção dos bebês como uma categoria social e analítica específica. Privilegiaremos aqui a apresentação das contribuições de Winnicott e Dolto, que, de acordo com Barbosa (2012), destacam-se dos demais, por seus importantes trabalhos que atestam as competências dos bebês e nos convocam a "pensar numa especificidade ainda mais peculiar" (p. 263). Enfatizamos ainda as contribuições de Emmi Pikler (1984) e sua abordagem, desenvolvida no Instituto Lóczy, e de Parseval e Bigeargeal (1985), ao reivindicar uma "Bébologie" (ou "bebêlogia"5).

Winnicott, em 1971 (apud NAFFAH NETO, 2007), em seu texto "The location of cultural experience", já argumentava em defesa de um "ponto de vista do bebê" e do quão

\footnotetext{
${ }^{5}$ Expressão presente em artigo de Regine Sirota (2007) sobre a indeterminação das fronteiras da idade.
} 
proveitoso ele poderia ser. De acordo com Naffah Neto, o texto é de fundamental importância, porque nele Winnicott expressa a perspectiva do ponto de vista do bebê, diferente daquela da mãe ou do observador externo. Contudo, para Winnicot, é apenas a partir da relação com o outro (a mãe suficientemente boa) que o bebê se torna sujeito/pessoa. Winnicott (1960, p. 585) define o período do desenvolvimento do bebê como "infancy", que antecede a aquisição da fala e no qual "a capacidade de lidar com fatores externos à onipotência infantil está em processo de formação". Essa primeira infância ligada ao bebê é ainda definida como "uma fase em que o bebê depende dos cuidados maternos, que são baseados na empatia, e não na compreensão daquilo que é ou poderia ser expresso verbalmente" (p. 588) ${ }^{7}$.

Em contraposição a essa ideia e defendendo a importância da linguagem e da comunicação para o desenvolvimento do bebê, apresentam-se as contribuições de Françoise Dolto (2005, p. 362), que se configurou como uma importante defensora da importância de conversarmos com os bebês, uma vez que assume que "o ser humano é um ser de linguagem desde sua concepção".

De acordo com Kupfer (2006, p. 571):

Dolto supunha que um bebê podia entender desde o seu nascimento o que lhe diziam à sua volta. Assim, a verdade precisava ser-lhe dita desde o início. Dolto relata inúmeros casos de bebês cujos problemas de alimentação ou de sono desapareciam, quando as supostas raízes de suas dificuldades Ihes eram explicadas.

A psicanalista também foi a idealizadora das Maisons Vertes - espaços onde bebês e crianças de até 3 anos de idade, acompanhadas por seus pais e sob a supervisão de psicanalistas, podiam ficar soltas, interagir com outros bebês e adultos, brincar e explorar o espaço e seus elementos. De acordo com Dolto (2005, p. 351), "a Maison Verte é uma intermediária entre o lar e o berçário, entre o lar e a creche". Ela relata que o fato de falarem diretamente ao bebê faz com que não sofram a síndrome de adaptação à creche e afirma: "o bebê entende tudo o que lhes dizemos" (idem, p. 353). A experiência de Dolto nas Maisons Vertes, os registros de cenas ali vividas e sua teoria da relevância da linguagem para o bebê, são até hoje referências importantes para os Estudos de bebês não apenas na psicanálise como na Sociologia e em outros campos do saber.

Também pautada na importância do diálogo com os bebês, a médica de família Emmi Pikler desenvolveu no Instituto Lóczy (Hungria), a partir da década de 1940, uma

\footnotetext{
${ }^{6}$ Que poderia ser por nós compreendido como primeira infância, para se diferenciar da expressão childhood, geralmente traduzida como infância.

${ }^{7}$ Texto original: "a phase in which the infant depends on maternal care that is based on maternal empathy rather than on understanding of what is or could be verbally expressed".
} 
abordagem que tem sido base para estudos e práticas com bebês em todo o mundo e que valoriza a autonomia, o brincar livre, o respeito e o diálogo. Nessa perspectiva, de acordo com Falk (2016), o bebê precisa ser ouvido (e respondido).

De algum modo, todas essas abordagens contribuem para a constituição de um campo de Estudos de bebês. Uma "Bebêlogia", nos termos de Parseval e Bigeargeal (1985).

\section{A ANTROPOLOGIA E OS BEBÊS}

No âmbito da Antropologia, as pesquisas conduzidas nas décadas de 1920 e 1930 por Margareth Mead têm sido apontadas como um marco nos estudos antropológicos das crianças. Além deles, os trabalhos de Benedict e Ward em 1973, destacados por Cohn (2009), e aqueles realizados por Hardman na década de 1970, apontados por Nunes (1999), são alguns dos que contribuíram para a constituição de uma "Antropologia da criança".

Os bebês aparecem em algumas pesquisas, tais como as de Morton (1996) ou as de Cohn $(2009,2015)$, mas quem, de fato, trouxe os bebês para o foco da cena na Antropologia foi a pesquisadora Alma Gottlieb (1998), que, após discutir a religião dos bebês, reivindicou uma antropologia dos bebês e de seus cuidadores (GOTTLIEB, 2009), e não apenas das crianças maiores.

Gottlieb (2009, p. 313) pondera sobre "a importância de se considerar os bebês sujeitos relevantes e benéficos para os objetivos da Antropologia" e aponta os motivos que poderiam justificar a exclusão dos bebês dos debates antropológicos até então. Essas razões contribuem para pensarmos além da Antropologia e nos fazem refletir sobre a ausência de bebês nas ciências sociais e nos estudos da infância de modo geral, tal como apontado por James (apud PIRES; NASCIMENTO, 2014) na epígrafe deste texto. Para GOTLIEB (2009, p.313), essas razões estão relacionadas aos seguintes fatos:

[...] as memórias e o status parental do próprio antropólogo, a questão problemática da agência dos bebês e sua suposta dependência de outras pessoas, suas rotinas ligadas às mulheres, sua aparente incapacidade de comunicação, sua propensão inconveniente a vazar através de vários orifícios, e seu aparente baixo grau de racionalidade.

No entanto, Gottlieb (2009, p.321) se remete aos estudos conduzidos por ela mesma na Costa do Marfim, entre os Beng, para sustentar que "de acordo com alguns pontos de vista, eles [bebês] podem ser considerados determinantes da vida das pessoas ao seu redor". Os estudos da autora apontam que

\footnotetext{
${ }^{8} \mathrm{O}$ termo deriva do inglês baby e do grego logos e, de acordo com as autoras, se constitui como a ciência que tem a ambição de estudar exaustivamente o bebê, em todas as suas formas e estados, sendo "bebólogo(a)" o(a) cientista que se especializa em Bebêlogia.
}

$\begin{array}{llllll}\text { (C) ETD-Educação Temática Digital } & \text { Campinas, SP } & \text { v.20 } & \text { n.4 } & \text { p. 924-946 } & \text { out./dez. } 2018\end{array}$


[...] os bebês Beng estão longe de ser criaturas indefesas sem opinião ou impacto sobre o mundo. Para os Beng, assim como para muitas sociedades não ocidentais, a suposta dependência total dos bebês, da forma como é amplamente pressuposta por antropólogos ocidentais, não existe - e, portanto, desafia a nossa ideologia implícita de que bebês são criaturas passivas, o que impediu a possibilidade de privilegiarmos os bebês como sujeitos legítimos, e muito menos como produtores de cultura (GOTTLIEB, 2009, p. 321).

A aparente incapacidade de comunicação dos bebês é tida como outro fator importante - considerada até mesmo uma barreira - que dificulta a realização de pesquisas com bebês. Em razão de tal contexto, a autora propõe que "para conseguirmos uma comunicação, é necessário que ajustemos os métodos de campo. [...] Desse modo, sugiro que faz sentido considerar a vida dos bebês como textos a serem lidos, embora possivelmente com um novo conjunto de lentes" (GOTTLIEB, 2009, p. 322).

A autora ressalta ainda que

pode ser tentador em nível metodológico permitir que outras pessoas falem pelos bebês - permitir que uma Antropologia dos bebês se torne uma Antropologia da primeira infância ${ }^{9}$ vista pelos outros. Isso seria pressupor que os bebês estão completamente sujeitos às estruturas imaginadas pelos adultos, incapazes de afirmar qualquer subjetividade. Portanto, é justamente esse aspecto que precisamos evitar, já que uma Antropologia da primeira infância deve incluir não apenas a consideração da perspectiva dos outros sobre os bebês, mas, e tão importante quanto uma Antropologia dos próprios bebês, baseada na premissa de que bebês podem eles próprios serem atores sociais (Morton, 1996), embora possam utilizar modos exóticos de comunicação. Já foram assinaladas anteriormente algumas mudanças metodológicas que uma Antropologia dos bebês bem desenvolvida necessitaria, incluindo sintonizar-se com formas somáticas de comunicação, com teorias locais sobre a comunicação dos bebês, assim como reconhecer que eles, assim como os adultos, são parte de um sistema cibernético no qual a identidade é definida como constitutiva da sociedade (Derné, 1992; Shweder \& Bourne, 1984). (GOTTLIEB, 2009, p. 326)

Por fim, Gottlieb (2009, p. 328) defende que "uma antropologia dos bebês (e de seus cuidadores) poderia contribuir para os permanentes debates sociais e filosóficos sobre 0 papel da educação na formatação da vida humana" e indica que "uma etnografia de bebês informada por trabalhos de campo poderia contribuir significativamente para essa discussão ainda em andamento" (p. 328).

\section{A SOCIOLOGIA DA INFÂNCIA E OS BEBÊS}

Temos argumentado em outros trabalhos e aqui reafirmamos que a Sociologia da Infância - de modo geral - pouco tem olhado para os bebês; no entanto, não podemos deixar de destacar neste artigo algumas de suas contribuições para o campo.

No que diz respeito à Sociologia do discurso sobre a criança e a infância na

\footnotetext{
${ }^{9}$ Vale ressaltar que a autora utiliza "primeira infância" para se referir apenas às crianças de 0 a 3 anos.
} 
perspectiva do construcionismo social, é relevante o argumento de que os sujeitos são produzidos por meio do discurso (JAMES; PROUT, 1997).

Ainda que os autores dessa perspectiva tenham focado seus debates no âmbito da produção da criança, eles oferecem uma base importante para o estudo de bebê e dos processos de subjetivação, tal como abordaremos adiante.

No âmbito da Sociologia da Infância estrutural-relacional, destaca-se a proposição de Alanen (2014) de utilização das contribuições da teoria dos campos sugeridos por Bourdieu para o estudo da infância, indicando a possibilidade de estudar, por exemplo, a família como um campo que, em conjunto com outros, impacta a "estruturação geracional", isto é, a construção ativa da geração.

Alanen (2001b, p. 130, grifos nossos, livre tradução) destaca que

\begin{abstract}
não se pode supor que geração opere apenas em domínios restritos da vida social; além da família, também a escola, as creches e outros domínios institucionalizados para crianças são espaços óbvios para a estruturação geracional [generationing]. E assim como 'gendering' 10 e 'classing' ${ }^{11}$, talvez mesmo 'racing' ${ }^{12}$, pode-se supor que estruturação geracional [generationing] ocorra também fora dessas instituições marcadas pela presença das crianças, de fato, em todos os domínios da vida social - na vida laboral e na política tanto quanto no campo cultural independentemente se as crianças são de fato vistas como presentes e atuantes nesses campos.
\end{abstract}

A partir de tal perspectiva e da teoria dos campos de Bourdieu, os bebês poderiam ser considerados como participantes 'amadores' de um campo, como aqueles atores que, mesmo participando nas interações diárias que produzem a vida cotidiana das sociedades concretas, não estão ativamente envolvidos nas lutas simbólicas do campo. Eles não seriam, nesse caso, definidos como "agentes", considerados nessa teoria como "profissionais" estrategicamente atuantes no interior do campo. Ainda assim, trata-se de uma abordagem que nos permite outros olhares para os bebês no diálogo com a Sociologia.

A Sociologia da Infância estrutural-categorial nos inspira a realizar pesquisas estatísticas sobre as condições de vida de bebês, índices de mortalidade, acesso a serviços de bem-estar, impactos da economia, utilização dos espaços públicos, etc. E no que se refere à Sociologia das Crianças, essa abordagem indica que os bebês, desde muito cedo, estão envolvidos em "rotinas culturais", ainda que de forma limitada inicialmente. 0 conceito de "culturas infantis" não é muito utilizado nessa abordagem ${ }^{13}$ para remeter aos

\footnotetext{
${ }^{10}$ Verbo relativo à produção do gênero.

${ }^{11}$ Verbo relativo à produção de classe.

12 Verbo relativo à produção da raça. Termo que pode ser traduzido para o português como "racialização".

${ }^{13}$ Por autores de língua inglesa
}

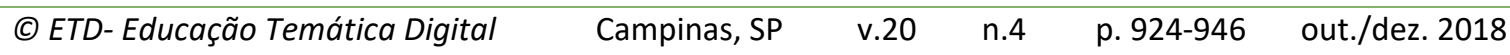


bebês ${ }^{14}$. De acordo com Corsaro (2011, p. 32, grifos do autor): ${ }^{15}$ “[...] os bebês são tratados como socialmente competentes ('como se' fossem capazes de intercâmbios sociais). Ao longo do tempo, devido a essa atitude de 'como se', as crianças passam de uma limitada a uma plena participação nas rotinas culturais".

Como observamos, o conceito de cultura de pares não é utilizado por Corsaro para se referir aos bebês, e, de acordo com o autor, apenas ao deixarem de ser bebês e se tornarem crianças é que ocorreria uma plena participação nas rotinas culturais. Confirmar ou refutar tal afirmação, neste caso, é tarefa por vir, que vai requerer olhar para os bebês e seus cotidianos e dialogar apropriadamente com os conceitos de cultura, infância e geração.

Poderíamos apontar ainda para uma Sociologia da pequena infância, com foco nos processos de socialização (PLAISANCE, 2004) ou uma Sociologia da primeira infância e dos pontos de vistas de bebês, a partir de diálogos com os estudos pós-estruturalistas desenvolvidos por filósofos da Diferença como Foucault, Deleuze, Guattari, Schérer (MOZÈRE, 2008). De acordo com Delgado e Nörnberg (2013, p. 153):

Mozère utiliza o aporte teórico das feministas anglo-saxônicas para defender o ponto de vista das crianças de zero a três anos. Seu trabalho de estudo e pesquisa foi sendo conduzido em creches da região de Paris, desde 1971, bem antes do desenvolvimento da sociologia da infância (BROUGÈRE; VANDENBROECK, 2007). Nas palavras da autora, trata-se de uma elaboração sociológica sobre o conhecimento do universo da pequena infância através de um trabalho de terreno meticuloso e microssociológico, conduzido num período de mais de três anos, o que permitiu analisar a experiência das crianças pequenas como uma ilustração da sua potência de agir e, em seguida, como uma criação de situações, de relações e de experiências (MOZÈRE, 2007, p. 172).

Inicialmente, ela questiona o que significa posicionar-se ao lado das crianças pequenas, se, como adultos, a maior parte de nossas percepções e representações é produzida por dispositivos de saberpoder, em espaços-tempos determinados e com uma dada função social. É na standpoint theory, das feministas anglo-saxônicas, que ela encontra inspiração para uma teoria do ponto de vista das crianças de zero a três anos, da escuta das suas vozes, do olhar e percepção dos seus desejos.

\footnotetext{
${ }^{14}$ Reconhecemos, no entanto, que no Brasil há um conjunto de trabalhos que utilizam os conceitos "culturas de pares" ou culturas infantis" para se remeter aos bebês, sem, contudo, problematizar se de fato os bebês se configuram um coletivo geracional infantil produtor de culturas.

${ }^{15}$ Por não ter mais de três linhas, esta citação deve fazer parte deste parágrafo.
}

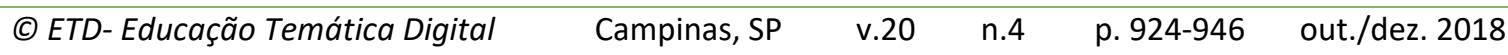


Além da influência da filosofia pós-estruturalista que sustenta o pensamento de Mozère, as pesquisas dessa autora são fortemente influenciadas pelos estudos e pelas ideias de Françoise Dolto, cujas principais características já foram aqui apresentadas.

Por fim, encerramos esta seção, destacando as contribuições da Sociologia da Infância brasileira para o estudo de bebês, ainda que no Brasil a Sociologia da Infância tenha se desenvolvido muito mais ligada aos debates educacionais da infância, no campo da educação infantil, tal como aponta Nascimento (2015). Dentre os autores brasileiros que têm se voltado para o estudo dos bebês em diálogo com a Sociologia, destacamos os estudos de Coutinho $(2009,2010,2014)$ que apontam para a ação social do bebê em contexto de creche, o de Cuzziol (2013) sobre a capacidade e a disponibilidade dos bebês para viver socioculturalmente, o de Castelli e Delgado (2015) sobre bebês que se relacionam com crianças mais velhas na educação infantil, os de Schmitt (2013) sobre as relações sociais de bebês em contexto de educação infantil, os de Ramos $(2012,2014)$ sobre a interação social dos bebês em berçários e seu impacto na organização pedagógica e o de Macedo (2016), que, ao discutir as crianças pequeninhas e a luta de classes, reivindica uma cidadania epistemológica para os bebês. Por fim, apontamos ainda para os estudos de Barbosa (201) sobre as especificidades pedagógicas da ação com bebês e o de Richter e Barbosa (2010) ao discutir o lugar dos bebês no currículo, de Gobbato (2011) sobre a educação de bebês nos diferentes contextos de vida coletiva da escola infantil e os de Fochi (2015), que, ao indagar o que fazem os bebês nos berçários, oferece-nos também fundamentos para os estudos de bebês na interface da educação com a Sociologia, a Psicologia, a Antropologia e a Arte. A metodologia de pesquisa predominante nesses estudos é a etnografia acompanhada de registros fotográficos, filmagens e descrição detalhada de cenas vividas.

\section{A FILOSOFIA E A INFÂNCIA}

$\mathrm{Na}$ história da Filosofia a criança foi, durante muito tempo, entendida como negatividade. Se tomarmos a Pedagogia tradicional, por exemplo, a infância era interpretada com referência a tudo que se passava como antítese da humanidade verdadeira. Era definida por oposição à sabedoria e à santidade. A criança devia ser submetida a uma vigilância constante, não devia fazer nada por si mesma, e o adulto devia mostrar-Ihe tudo. Foi em Nietzsche (1997), no livro Assim falava Zaratustra, que as crianças foram consideradas em sua positividade, na medida em que ele, na descrição das três metamorfoses do espírito, considerou a criança como o último estágio do espírito humano. Quando o homem chega à criança, é um novo recomeço, não mais o camelo que carrega o fardo da história e dos valores, nem mesmo o leão que diz não aos valores, mas a criança que inaugura o novo. Uma positividade se instaura na Filosofia e no pensamento, ao olhar a criança, e essa positividade se estende, ao olhar para o bebê. 


\section{A Filosofia e os bebês}

É também a partir da Filosofia que podemos afirmar que bebês vivenciam a infância em várias dimensões do tempo, já que esse não se apresenta da mesma maneira em todas as experiências. Bebês habitam, também, na dimensão do tempo aion, tal como Heráclito (1978) pronunciou no fragmento 52 de Éfeso. Aion é a estrutura temporal por trás de toda construção no tempo, é a criança que brinca e que não se submete à lógica dos dispositivos. Na dimensão cronos, o bebê vivencia a infância como uma primeira etapa do tempo histórico de sua vida - como convém ao cronos. O bebê faz experiência, experimentações, e habita a infância nessa perspectiva aion. Uma infância no tempo aion e no tempo intempestivo (tal como consagrou Deleuze a partir de Nietsche) é a emergência de uma diferença desestabilizadora das formas vigentes, a qual nos separa do que somos e nos coloca uma exigência de criação, que escapa também de uma infância na qual os dispositivos de saber/poder impõem a todos uma mesma infância. Trata-se de uma infância vivida - emprestando um conceito de Deleuze - no plano da imanência, ou seja, importa pensar a vida do bebê sem transcendência, os conceitos não vêm de fora, são extraídos dos próprios gestos e movimentos deles, da sua vida singular: uma vida. Singularidade. Devir (TEBET; ABRAMOWICZ, 2014).

Nesse sentido, se, por um lado, é possível subsidiar pesquisas como as de Mozère (2007, 2008) ou de Olson (2017) sobre a força do desejo e a experimentação na prática pedagógica em contexto de educação infantil, por outro lado, a força e a potência do bebê são destacadas por Leclercq, que aponta para as contribuições dos bebês para a filosofia. Em seu artigo intitulado "Deleuze e os bebês", Leclercq (2002) destaca o papel desempenhado pela imagem do bebê na filosofia deleuziana.

$\mathrm{Na}$ obra de Deleuze, os bebês são configurados a partir dos conceitos de vida singular e imanência, o que implica compreendê-los no âmbito singular da diferença e da pré-individualidade, tendo em vista que, de acordo com o autor, são a singularidade e a diferença que marcam a condição pré-individual do ser: "Singular sem ser individual, eis o estado do ser pré-individual. Ele é diferença, disparidade, disparação" (DELEUZE, 2010, p. 118).

Esse conceito de singularidade pré-individual é tomado por Deleuze (ano) de Simondon (2003), que a define no sentido pré-socrático, como a condição do possível e do indeterminado, e não como o contrário do homem. Uma condição que possibilita os processos de individuação que acontecem ao longo da vida e que se faz presente em todos os seres, coexistindo com o indivíduo, que é apenas uma das fases do ser.

Pensar o bebê e seus processos de individuação, nesse sentido, é compreender o bebê como um ser muito mais completo e potente do que a ideia de ser individuado. De 
acordo com Simondon (2003, p. 102),

para pensar a individuação é necessário considerar o ser, não como substância, matéria ou forma, mas como sistema tenso, supersaturado, acima do nível da unidade; [...] o ser concreto ou ser completo, isto é, o ser pré-individual, é um ser que é mais que uma unidade. [...] a unidade e a identidade só se aplicam a uma das fases do ser, posterior à operação de individuação; essas noções não podem ajudar a descobrir o princípio de individuação.

Ou seja, falar de bebê a partir das noções de individuação, pré-individual, singularidade e devir é falar de um ser que guarda todos os possíveis, que permitem o processo de individuação. Ressaltar o caráter pré-individual do bebê, portanto, não significa negar o bebê como um ser (uma pessoa) que, desde o seu nascimento, participa e interage com os elementos humanos e não humanos da sociedade, impacta sobre ela e constrói aprendizagens diversas. Significa reconhecer que o bebê o faz de um modo singular, ainda abrindo o campo do possível e das possibilidades, na medida em que não foi assujeitado às normas e aos padrões da sociedade, não foi submetido totalmente aos dispositivos de construção de indivíduos. E é esta condição que torna o bebê um ser tão potente e singular.

A partir de tal compreensão, Deleuze (1995, s.p.) faz a seguinte afirmação, destacando os bebês como exemplo potente dessa singularidade não individual:

As singularidades ou os acontecimentos constitutivos de uma vida coexistem com os acidentes da vida correspondente, mas não se agrupam nem se dividem da mesma maneira. Eles se comunicam entre si de uma maneira completamente diferente da dos indivíduos. Parece mesmo que uma vida singular pode passar sem qualquer individualidade ou sem qualquer outro concomitante que a individualize. Por exemplo, os recém-nascidos são todos parecidos e não têm nenhuma individualidade; mas eles têm singularidades, um sorriso, um gesto, uma careta, acontecimentos, que não são características subjetivas. Os recém-nascidos, em meio a todos os sofrimentos e fraquezas, são atravessados por uma vida imanente que é pura potência, e até mesmo beatitude.

Evidencia-se, assim, a importância não apenas da filosofia para pensar os bebês, mas da figura analítica/conceitual do bebê para a filosofia, bem como de conceitos da filosofia que apoiam estudos sobre bebês em outros campos, como a Sociologia proposta por Mozère $(2007,2008)$ e a Pedagogia desenvolvida por Olson (2017). 


\title{
7 A GEOGRAFIA DE BEBÊS E A CARTOGRAFIA
}

A partir das ideias de Deleuze (1997), Deligny (2008), Guattari (1985), Guattari e Rolnik (1986), Lopes (2012), Lopes e Vasconcellos (2006), Rolnik (1989) e Tuan (2013) e de um olhar para a experiência geográfica de bebês, destaca-se o modo como essas experiências atuam nos processos de individuação, subjetivação e singularização. Tal perspectiva também é destacada por Holt (2013, p. 645, livre tradução), geógrafa de bebês, que afirma, em diálogo com Judith Butler, que

\begin{abstract}
a atenção para as geografias diárias de bebês, portanto, tem o potencial para desvendar como os indivíduos são subjetivados; como o poder se torna uma parte incorporada das identidades subjetivas dos indivíduos, operando de forma criativa para produzir indivíduos com ação social [agency], e, ao mesmo tempo, limitando e circunscrevendo subjetividades apropriadas.
\end{abstract}

Defendemos que olhar para as geografias cotidianas de bebês, bem como para suas ações cotidianas, nos permite ainda obter elementos para um estudo dos "modos de subjetivação singulares" que estão ligados a "processos de singularização", esses descritos por Guattari e Rolnik (1986, p. 17) como

\begin{abstract}
uma maneira de recusar todos esses modos de encodificação preestabelecidos, todos esses modos de manipulação e de telecomando, recusá-los para construir, de certa forma, modos de sensibilidade, modos de relação com o outro, modos de produção, modos de criatividade que produzam uma subjetividade singular. Uma singularização existencial que coincida com um desejo, com um gosto de viver, com uma vontade de construir o mundo no qual nos encontramos, com a instauração de dispositivos para mudar os tipos de sociedade, os tipos de valores que não são os nossos.
\end{abstract}

Assim, uma geografia de bebês deve olhar para os modos como os bebês experienciam o espaço; para os movimentos possíveis e para as relações que fazem do espaço um lugar dotado de valor (TUAN, 2013). Nesse sentido, são significativos os debates propostos por Harrison e Sumsion (2014) e a abordagem proposta por Clark e Moss (2011), que propõem a realização de tours com as crianças e mapas associados a outras metodologias de pesquisa como estratégias potentes para o estudo das experiências vividas pelas crianças, e não apenas para o conhecimento adquirido ou os cuidados recebidos.

\section{PESQUISAS COM CRIANÇAS, PESQUISAS COM BEBÊS E A CARTOGRAFIA}

A importância de pesquisas que revelem o ponto de vista de crianças sobre as questões sociais que as envolvem tem sido evidenciada e discutida já há algum tempo, a exemplo dos trabalhos de Alanen (2001a), Alderson (2005) e Clark e Moss (2011).

Essa perspectiva parte da compreensão de que o saber é uma construção ideológica e discursiva, e não um reflexo da realidade e, desse modo, ele é sempre 'situado' e depende do ponto de vista de seus envolvidos. Assim como ocorreu no caso das mulheres e também dos negros, aceitar a perspectiva das crianças como algo necessário às pesquisas sociais foi 
por muito tempo uma barreira a vencer. Todavia, ainda que essa questão já tenha caminhado alguns passos no âmbito das produções acadêmicas, hoje ainda é comum que o ponto de vista das crianças seja desconsiderado em pesquisas sobre meio ambiente, trânsito, moradia e outras questões que afetam diretamente suas vidas, fato bastante contestado por autores como Qvortrup (2011).

No Brasil, o ponto de vista das crianças tem sido incorporado especialmente em pesquisas sobre educação e saúde. Ainda que de modo restrito, tal fato pode ser compreendido como um avanço, no que diz respeito à valorização das experiências e dos pontos de vista das crianças. No contexto britânico, Clark e Moss (2011, p. 5) afirmam que em 2002 "era incomum ver a perspectiva de crianças pequenas aceitas como parte necessária na exploração da qualidade da provisão", pois havia muitas barreiras para que as crianças tivessem seus saberes reconhecidos.

A abordagem do mosaico proposta por Clark e Moss (2011, p. 5) fornece instrumentos para possibilitar a construção de conhecimento em parceria com crianças pequenas a partir de diferentes formas de comunicação, "escolhidas por estarem próximas ao modo como crianças pequenas poderiam escolher para se comunicar com os amigos e a família". Essa perspectiva nos oferece possibilidades interessantes, de acordo com as peças do mosaico selecionadas. E aqui defendemos, sobretudo, as possibilidades que podem emergir de pesquisas que combinem a observação com a produção de mapas, uma vez que se compreende o importante papel que o espaço desempenha nos processos educativos que envolvem os bebês.

A cartografia (DELEUZE; GUATTARI, 2000; DELIGNY, 2008; GUATTARI; ROLNIK, 1986; PELBART, 2013) é aqui entendida como uma rica possibilidade metodológica nos Estudos de bebês, na medida em que nos permite ver e traçar, numa perspectiva comum àquela proposta por Deligny ${ }^{16}$, "um comum impossível, salpicado de desvios, de gestos, de temporalidades, de nós, de atratores estranhos" (PELBART, 2013, p. 285). O trabalho de Deligny e suas contribuições para os Estudos de bebês podem ser mais bem compreendidos a partir da seguinte explanação:

Fernand Deligny transcreve as linhas e trajetos de crianças autistas, faz mapas: distingue cuidadosamente as "linhas de errância" e as "linhas costumeiras". E isso não vale somente para os passeios, há também mapas de percepções, mapas de gestos (cozinhar ou recolher madeira), com gestos costumeiros e gestos erráticos. O mesmo para a linguagem, se existir uma. Fernand Deligny abriu suas linhas de escrita para linhas de vida. E constantemente as linhas se cruzam, se superpõem por um instante, se seguem por um certo tempo. Uma linha errática se superpôs a uma linha costumeira e aí a criança faz algo que não pertence mais exatamente a nenhuma das duas, reencontra algo que havia perdido - que aconteceu? - ou

${ }^{16}$ Fernand Deligny (1913-1996), educador francês que trabalhou, sobretudo, com crianças autistas.

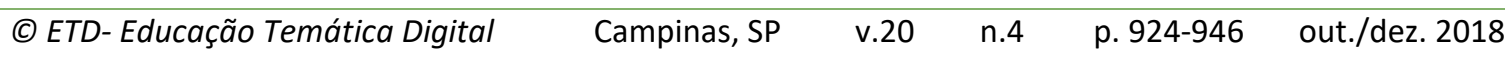


então ela salta, agita as mãos, minúsculo e rápido movimento - mas seu próprio gesto emite, por sua vez, diversas linhas.

Perceber, como diz Deligny, que essas linhas não querem dizer nada é uma questão de cartografia. Elas nos compõem, assim como compõem nosso mapa. Elas se transformam e podem mesmo penetrar uma na outra, como na forma de rizomas. Certamente não têm nada a ver com a linguagem; ao contrário, é a linguagem que deve segui-las, é a escrita que deve se alimentar delas entre suas próprias linhas (DELEUZE; GUATTARI, 1995, p. 77).

Exatamente isto é que fazemos, ao cartografar bebês: traçar seus mínimos gestos e movimentos, suas expressões, cuja linguagem deve perseguir.

Alguns trabalhos nessa perspectiva são os desenvolvidos por Gallacher (2005); Oliveira (2015); e Sumsion, Stratigos e Bradley (2014) e trazidos para o debate. Vejamos a seguir.

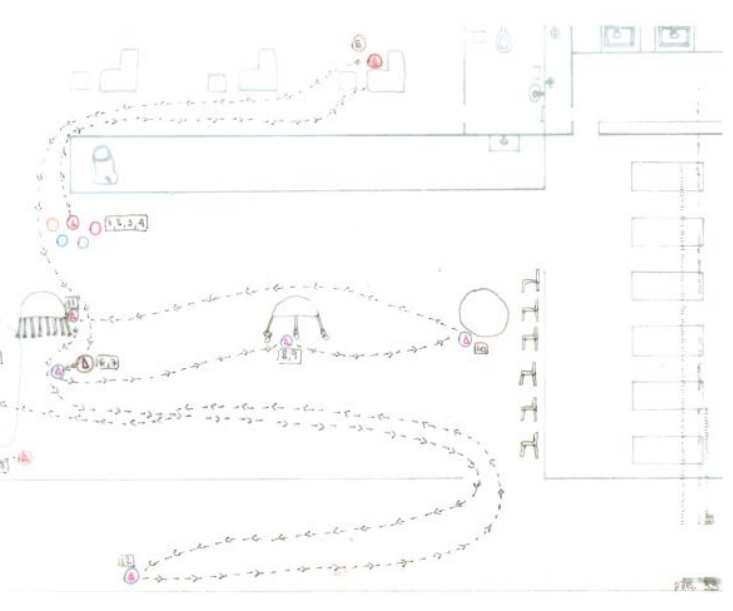

FIGURA 3 - Trajeto de uma bebê

(Oliveira, 2015, p.33).

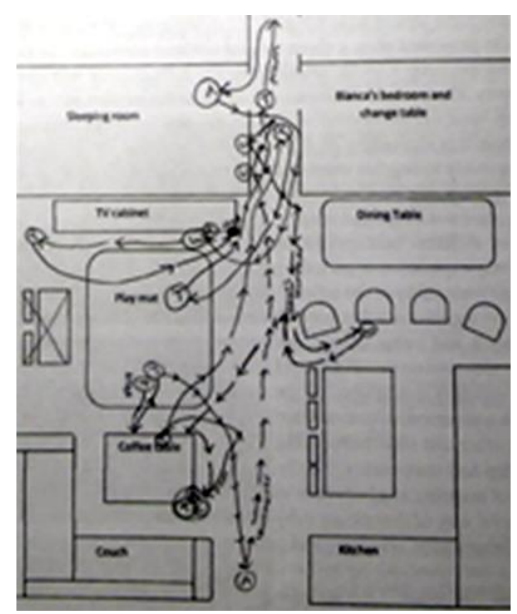

FIGURA 4 - Movimentos de bebês em uma creche australiana

(Sumsion, Stratigos e Bradley, 2014, p. 58). 


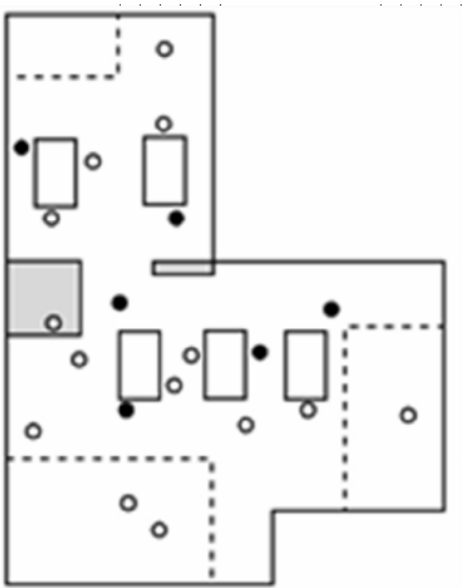

FIGURA 5 - Recepção das Crianças/Hora da brincadeira Livre Fonte: Gallacher (2005, p.246)

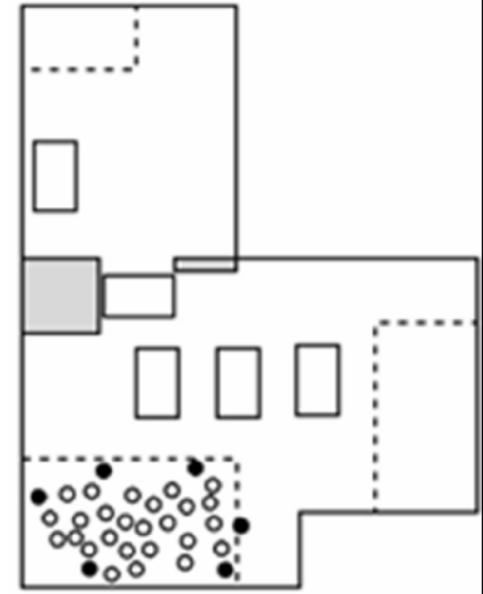

FIGURA 6-Hora da História Fonte: Gallacher (2005, p. 250)

Tais abordagens se mostram promissoras, na medida em que permitem aos investigadores seguir de forma mais eficaz os minúsculos, mesmo que mínimos, gestos e eventos que compõem a vida de bebês, contribuindo para uma melhor compreensão de bebês a partir de sua perspectiva, agência e protagonismo.

\title{
9 CONSIDERAÇÕES FINAIS: ALGUMAS PALAVRAS SOBRE OS ESTUDOS DE BEBÊS
}

Este texto diagrama e busca apontar algumas possibilidades para os Estudos de bebês e os modos pelos quais eles traçam seus caminhos e desempenham ação social [agency] de maneira singular. Traz a noção de que bebês e sua condição pré-individual carregam em potência mil possibilidades de se configurar em suas diferenças, por meio de processos de individuação e a partir dos múltiplos dispositivos de constituição de sujeitos: como o da sexualidade, o da infância etc. Por isso, cartografar seus percursos errantes, afe(c)tos, encontros, etc. é traçar seus gestos e movimentos, suas expressões, cuja linguagem deverá perseguir. Acompanhar bebês não é compor sentidos já estruturados podemos traçar os caminhos já costumeiros dos adultos, como diria Deligny, ou as linhas de errância.

\begin{abstract}
[As linhas de errância] parecem incompreensíveis para o adulto e os projetos por ele formulados. Por que uma criança faria um desvio extremamente longo pelo rio se ele está carregado de madeira para o forno e se poderia seguir uma linha reta e mais curta? Por que ele descasca uma laranja se não quer comê-la? São, pois, linhas de errância, linhas erráticas que inscrevem o erro no "bom senso" do adulto "normal”. (MIGUEL, 2015, p. 59-60 apud MUNARI, 2017)
\end{abstract}

A cartografia, nesse sentido, nos permite colocar a linguagem em seu limite, já que os sentidos não estão dados a priori. Os bebês se expressam por gestos (às vezes, mínimos e minúsculos), balbuciam, sibilam etc., sem que a compreensão e os sentidos para os adultos 
se façam imediatamente. A cartografia, nesse sentido, nos oferece possibilidades metodológicas interessantes.

O trabalho com os bebês, a partir desses conceitos, aponta para a necessidade de metodologias de pesquisa que sejam capazes de compreender os bebês, seus movimentos e as redes tecidas por eles, com eles e para eles. Seus fluxos e seus desejos. Trata-se de diagramar a maneira singular pela qual um bebê se constitui e se subjetiva a si e ao outro e os processos de individuação que vivencia. Finalmente, este texto defende a ideia de que estudar bebês é cartografar os trajetos e os afectos que constituem seus movimentos e registrar, assim, as singularidades inerentes à condição pré-individual do bebê. Ao mesmo tempo em que estudar bebês é colocar a linguagem, a epistemologia e as metodologias em tensão, já que os sentidos não estão dados a priori.

Este é o horizonte que se coloca para as pesquisas com bebês a partir da abordagem aqui apresentada, na qual tentamos defender a ideia que é expressa pelas crianças, quando dizem: "Eu não sou mais bebê". A ideia de que um bebê não é uma criança se assenta no reconhecimento de que diversos têm sido os autores e os espaços nos quais se têm distinguido a imagem de um bebê da imagem de uma criança. Construir uma imagem de pensamento relativa ao bebê significa apontar e buscar as múltiplas possibilidades que estão postas de maneira singular, na constituição de uma pessoa, ou seja, aceitar que há na constituição de um indivíduo, singularidades, formas únicas, diferenças, que podem fazer fugir formas hegemônicas de constituição de indivíduos e que ampliam as possibilidades de fazer indivíduos e de produzir uma vida. Ou seja, o bebê vive em um bolsão de possibilidades, singulares, antes - ou ao mesmo tempo - de se individuar e de podermos tentar diagramar suas possibilidades a partir de linhas e de cartografias nas quais as emoções, os gestos, os sons se fazem ao mesmo tempo, de maneira singular.

\section{REFERÊNCIAS}

ALANEN, Leena. Estudos feministas/estudos da infância: paralelos, ligações e perspectivas. In: CASTRO, L. R. (Org.). Crianças e jovens na construção da cultura. Rio de Janeiro: NAU, 2001a. p. 6992.

ALANEN, Leena. Childhood as a generational condition: children's daily lives in a central Finland town. In: ALANEN, Leena; MAYALL, Berry. Conceptualizing child-adult relations. London and New York: Routledge/Falmer, 2001b. p.129-144.

ALANEN, Leena. Repensando a infância, com Bourdieu. Revista NUPEM, Campo Mourão, v. 6, n.11, p. 39-55, jul./dez. 2014.

ALDERSON, Priscilla. As crianças como pesquisadoras: os efeitos dos direitos de participação sobre a metodologia de pesquisa. Educação e Sociedade, Campinas, v. 26, n. 91, p. 419-442, maio/ago. 2005.

ARIÈS, Phillipe. História social da criança e da família. Rio de Janeiro: Guanabara Koogan, 1981. 
BARBOSA, Maria Carmen Silveira; DELGADO, Ana Cristina Coll; TOMÁS, Catarina. Estudos da infância, estudos da criança: quais campos? Quais teorias? Quais questões? Quais métodos? Revista InterAção, Goiânia, v. 41, n.1, p. 103-122, jan./abr. 2016.

BARBOSA, Maria Carmen Silveira. As especificidades da ação pedagógica com os bebês. BRASIL. Ministério da Educação. Consulta pública sobre orientações curriculares nacionais da Educação Infantil. Brasília, DF: MEC/SEB/COEDI, 2010.

BARBOSA, Denise Carvalho. A clínica psicanalítica: de crianças a bebês, uma especificidade. Estilos clin., São Paulo, v. 17, n. 2, p. 262-277, dez. 2012.

CASTELLI, Carolina Machado; DELGADO Ana Cristina Coll. Bebês que se relacionam com crianças mais velhas: cuidados e conflitos na educação infantil. In: REUNIÃO NACIONAL DA ANPEd, 37., 04 a 08 de outubro de 2015, UFSC - Florianópolis. Disponível em:

http://www.anped.org.br/sites/default/files/trabalho-gt07-3704.pdf Acesso em: 05 jan. 2018.

CLARK, Alison; MOSS, Peter. Listening to young children: The mosaic approach. 2. ed. Londres: NCB, 2011.

COHN, Clarice. Antropologia da infância. 2. ed. Rio de Janeiro: Zahar, 2009.

COHN, Clarice. Entrevista. In: ABRAMOWICZ, Anete et al. Estudos da Infância no Brasil: temas e debates na década de 1970 a 2010. São Carlos: EdUFSCar, 2015.

CORSARO, William. Sociologia da infância. 2. ed. Tradução de Lia Gabriele R. Reis. Revisão técnica de Maria Letícia B. P. Nascimento. Porto Alegre: Artmed, 2011.

COUTINHO, Ângela Maria Scalabrin. O estudo das relações sociais dos bebês na creche: uma abordagem interdisciplinar. Zero-a-Seis, São Paulo, v. 11, n. 19, p. 17-25, 2009.

COUTINHO, Ângela Maria Scalabrin . A ação social dos bebês: um estudo etnográfico no contexto da creche. 2010.Tese (Doutorado) - Instituto de Educação, Universidade do Minho, Braga, Portugal, 2010. Disponível em: https://repositorium.sdum.uminho.pt/bitstream/1822/11336/1/tese.pdf. Acesso em: 04 jan. 2018.

COUTINHO, Ângela Maria Scalabrin . Os bebês e a brincadeira: questões para pensar a docência. Da investigação às práticas, Lisboa, v. 4, n. 1, p. 31-43, 2014.

CUZZIOL, Ana Paula Gomes. "Pequenos-gigantes" entre si: notas etnográficas acerca da capacidade e da disponibilidade dos BEBÊS em viver socioculturalmente. 2013. Dissertação (Mestrado em Educação) - Faculdade de Educação, Universidade Federal Fluminense, Niterói, 2013.

DELGADO, Ana Cristina Coll; NÖRNBERG, Marta. Do abrir-se aos pontos de vista e forças do desejo dos bebês e crianças bem pequenas. Linhas Críticas, Brasília, v. 19, n. 38, jan./abr., p. 147-167, 2013.

DELEUZE, Gilles. A imanência: uma vida... Tradução de Tomaz Tadeu da Silva. Disponível em: http://pt.scribd.com/doc/7182897/Deleuze-Gilles-A-Imanencia-Uma-Vida Acesso em: 09 mar. 2017. Publicado originalmente em Philosophie, n. 47. p. 3-7, 1995. 
DELEUZE, Gilles. O que as crianças dizem. In: DELEUZE, Gilles. Crítica e clínica. Tradução de Peter Pál Pelbart. São Paulo: Editora. 34, 1997. p. 73-79.

DELEUZE, Gilles . Gilbert Simondon, o indivíduo e sua gênese físico-biológica [1966]. In:

DELEUZE, Gilles. A ilha deserta. São Paulo: lluminuras, 2010.

DELEUZE, Gilles; GUATTARI, Félix. Mil platôs. Capitalismo e Esquizofrenia. v. 2. São Paulo: Editora 34, 1995. Volume 2. (Coleção Trans)

DELEUZE, Gilles; GUATTARI, Félix . Mil platôs. Capitalismo e Esquizofrenia. v. 1. São Paulo: Editora 34, 2000.

DELIGNY, Fernand. L'Arachnéen et autres textes. París: Éditions l'Arachnéen, 2008.

FALK, Judith (Org). Abordagem Pikler - educação infantil. São Paulo: Omnisciência, 2016.

FOCHI, Paulo. Afinal, o que os bebês fazem no berçário? Porto Alegre: Penso, 2015.

FONTANEL, Béatrice ; D'HARCOURT, Claire. L'épopée des bébés: une histoire des petits d'hommes. Paris: Ed. de La Martinière, 2010.

FORBES, Jorge. A psicanalista, a mulher, a interpretação: Françoise Dolto. Texto publicado em 06 dez. 2012. Disponível em: http://www.ipla.com.br/editorias/acontece/psicanalise-francoisedolto.html Acesso em: 07 jan. 2018.

GALLACHER, Lesley. 'The terrible twos': Gaining control in the nursery?. Children's Geographies, v. 3, n. 2, p. 243-264, 2005.

GOBBATO, Carolina. 'Os bebês estão por todos os espaços!': um estudo sobre a educação de bebês nos diferentes contextos de vida coletiva da escola infantil. 2011. Disponível em:

http://www.anped.org.br/sites/default/files/gt07-2325_int.pdf Acesso em 05 jan. 2018.

GOTTLIEB, Alma. Do infants have religion? The spiritual lives of Beng babies. American Anthropologist, v. 100, n. 1, p.122-135, 1998.

GOTTLIEB, Alma. Para onde foram os bebês? Em busca de uma Antropologia de bebês (e de seus cuidadores). Psicol. USP [online], v. 20, n. 3, p. 313-336, 2009.

GUATTARI, F. Revolução molecular: pulsações políticas do desejo. São Paulo: Brasiliense, 1985.

GUATTARI, F.; ROLNIK, S. Micropolítica: cartografias do desejo. Petrópolis: Vozes, 1986.

HARRISON, Linda; SUMSION, Jennifer. (Ed.). Lived spaces of infant-toddler education and care: Exploring diverse perspectives on theory, research and practice. New York, London: Springer Netherlands, 2014. (Series International Perspectives on Early Childhood Education and Development, v. 11).

HERÁCLITO. Doxografia e fragmentos. In: SOUZA, J. C. (Supervisão). Os pré-socráticos: fragmentos, doxografia e comentários. São Paulo: Abril Cultural, 1978. (Coleção Os pensadores). 
HOLT, Louise. Exploring the emergence of the subject in power: infant geographies. Environment and Planning: Society and Space, v. 31, n. 4, p. 645-663, 2013.

KOHAN, Walter. Infância, estrangeiridade e ignorância: ensaios de filosofia e educação. Belo Horizonte: Autêntica, 2007.

KUPFER, Maria Cristina Machado. Françoise Dolto: uma médica de educação. Rev. Mal-Estar Subj. [online]. v.6, n.2, 2006, pp. 561-574 . Disponível em: http://pepsic.bvsalud.org/scielo.php?script=sci arttext\&pid=S151861482006000200013\&lng=pt\&nrm=iso Acesso em: 10 jan. 2018.

LECLERCQ, Stéfan. Deleuze e os bebês. Educação \& Realidade, Porto Alegre, v. 27, n. 2, 2002.

LOPES, Jader Janer Moreira. Os bebês, as crianças pequenas e suas condições histórico geográficas: algumas notas para debate teórico-metodológico. Educação em Foco, Juiz de Fora, edição especial, p. 151-161, 2012.

LOPES, Jader Janer Moreira; VASCONCELLOS, Tânia de. Geografia da infância: territorialidades infantis. Currículo sem fronteiras, Porto, Portugal, v. 6, n. 1, p. 103-127, 2006.

MACEDO, Elina Elias de et al. Crianças pequenininhas e a luta de classes. 2016. Tese (Doutorado) Faculdade de Educação, Universidade Estadual de Campinas, Campinas, 2016.

MIGUEL, M. Guerrilha e resistência em Cévennes. A cartografia de Fernand Deligny e a busca por novas semióticas deleuzo-guattarianas. Revista Trágica: estudos de filosofia da imanência, Rio de Janeiro, v. 8, n. 1, p. 57, 2015.

MORTON, Helen. Becoming Tongan. Honolulu: University of Hawaii Press, 1996. 343 p.

MOZÈRE, Liane. "Du côté" des jeunes enfants ou comment appréhender le désir en sociologie? In: BROUGÈRE, Gilles; VANDENBROECK, Michel (Dir.). Repenser l' éducation des jeunes enfants. Bruxelles: Éditions Scientifiques Internationales, 2007. p. 165-188.

MOZÈRE, Liane. On n'apprend pas à un enfant à marcher. Le Portique [En ligne], n. 21, 2008. Disponível em: http://journals.openedition.org/leportique/1783 Acesso em: 05 jan. 2018.

MUNARI, Silvio. Linhas de errância: vidas precárias e pedagogias. Tese (Doutorado) - Programa de Pós-Graduação em Educação, Universidade Federal de São Carlos-PPGE/UFSCar, São Carlos, 2017.

NAFFAH NETO, Alfredo. A noção de experiência no pensamento de Winnicott como conceito diferencial na história da psicanálise. Natureza Humana, São Paulo, v. 9, n. 2, p. 221-242, dez. 2007. Disponível em: http://pepsic.bvsalud.org/scielo.php?script=sci arttext\&pid=S151724302007000200001\&lng=pt\&nrm=iso . Acesso em: 07 jan. 2018.

NASCIMENTO, Maria Letícia B. P. Como se conduz a pesquisa da infância quando a educação é mais um campo a compor seus estudos? Alguns elementos para discussão. Currículo sem Fronteiras, Porto, Portugal, v. 15, p. 79-93, 2015.

NIETZCHE, Friedrich. Assim falava Zaratustra. Lisboa: Ediclube, 1997. 
NUNES, Angela. A sociedade das crianças A'uwẽ-Xavante (por uma antropologia da criança). Lisboa: Instituto de Inovação Educacional, 1999. (Coleção Temas de investigação, v. 8).

OLIVEIRA, Julia Tachikawa de. Trajetórias e caminhos: cartografias dos bebês (Texto para qualificação de dissertação de mestrado) - Programa de Pós-Graduação em Educação, Universidade Federal de São Carlos-PPGE/UFSCar, São Carlos, 2015.

OLSON, Liselott. Movimento e experimentação na aprendizagem de crianças pequenas. In: ABRAMOWICZ, Anete; TEBET, Gabriela. Infância e pós-estruturalismo. São Paulo : Porto de Ideias, 2017.

PARSEVAL, Geneviève Delaisi de; BIGEARGEAL J. Objectif bébé. Une nouvelle science, la bébologie, Paris: Ed. du Seuil, 1985.

PELBART, P. O avesso do niilismo: cartografias do esgotamento. São Paulo: N-1 Edições, 2013.

PIKLER, Emmi. Moverse en libertad: desarrollo de la motricidad global. Narcea Ediciones, 1984.

PIRES, Flávia Ferreira; NASCIMENTO, Maria Letícia Barros Pedroso. O propósito crítico. Entrevista com Allison James. Educação e Sociedade, Campinas, v. 35, n. 128, p.931-950, jul./set. 2014.

Disponível em: http://www.scielo.br/pdf/es/v35n128/0101-7330-es-35-128-00931.pdf. Acesso em: 07 jan. 2018

PLAISANCE, Eric. Para uma sociologia da pequena infância. Educação e Sociedade, Campinas, v. 25, n. 86, p. 221-241, abr. 2004. Disponível em:

http://www.scielo.br/scielo.php?script=sci arttext\&pid=S0101-73302004000100011 Acesso em: 04 jan. 2018.

QVORTRUP, Jens. Nove teses sobre a "infância como um fenômeno social". Pro-Posições, Campinas, v. 22, n. 1(64), p.199-211, 2011.

RAMOS, Tacyana. As crianças no centro da organização pedagógica: o que os bebês nos ensinam? In: REUNIÃO ANUAL DA ASSOCIAÇÃO NACIONAL DE PÓS-GRADUAÇÃO E PESQUISA EM EDUCAÇÃO, 35., 21 a 24 de outubro de 2012, Porto de Galinhas-PE. Disponível em:

http://www.anped.org.br/sites/default/files/gt07-2325 res.pdf . Acesso em: 04 jan. 2018

RAMOS, Tacyana . Observação, escuta e interlocução com o bebê nas práticas cotidianas da educação infantil. In: SEMINÁRIO DE GRUPOS DE PESQUISA SOBRE CRIANÇAS E INFÂNCIAS GRUPECI, de 24 a 27 de setembro de 2014, Goiânia- Goiás. Disponível em http://www.grupeci.fe.ufg.br/up/693/o/RE60.PDF Acesso em: 05 jan. 2018.

RICHTER, Sandra; BARBOSA, Maria Carmen Silveira. Os bebês interrogam o currículo: as múltiplas linguagens na creche. Educação (UFSM), v. 1, n. 1, p. 85-96, 2010.

ROLNIK, Suely. Cartografia sentimental, transformações contemporâneas do desejo. São Paulo: Estação Liberdade, 1989.

SCHMITT, Rosinete Valdeci. O encontro com bebês e entre bebês: uma análise do entrelaçamento das relações. In: ROCHA, Eloisa; KRAMER, Sônia (Org.). Educação Infantil: enfoques em diálogo. Campinas: Papirus, 2013. p. 17-33. 
SIMONDON, Gilbert. A gênese do indivíduo. In: PELBART, P. P.; COSTA, R. (Org.) Cadernos de subjetividade: o reencantamento do concreto. Tradução de Ivana Medeiros. São Paulo: Hucitec, 2003. p. 97-117.

SIROTA, Régine. A indeterminação das fronteiras da idade. Perspectiva, Florianópolis, v. 25, n. 1, p. 41-56, 2007.

SUMSION, Jennifer; STRATIGOS, Tina; BRADLEY, Bem. Babies in space. In: HARRISON, Linda; SUMSION, Jennifer. Lived spaces of infant-toddler education and care: Exploring diverse perspectives on theory, research and practice. Ney York London: Springer Netherlands, 2014. (Series International perspectives on early childhood education and development, v. 11).

TEBET, Gabriela; ABRAMOWICZ, Anete. O bebê interroga a sociologia da infância. Linhas Críticas, Brasília, v. 20, n. 41, 2014.

TUAN, Yi-Fu. Espaço e lugar: a perspectiva da experiência. Londrina: Eduel, 2013. 248 p.

WINNICOTT, D. W. The theory of the parent-infant relationship. In: The International Journal of Psycho-Analysis, n. 41, p. 585-595, 1960. Disponível em: http://icpla.edu/wpcontent/uploads/2012/10/Winnicott-D.-The-Theory-of-the-Parent-Infant-Relationship-IJPA-Vol.-41pps.-585-595.pdf Acesso em: 03 jan. 2018.

*Revisão gramatical do texto sob responsabilidade de:

Leda Farah - E-mail: leda.farah@terra.com.br 